manganese, and contains $0 \cdot 154$ per cent copper. The colour of laccase solution containing $0.015 \mathrm{mgm}$. copper per c.c. is of the same intensity as a 7 per cent copper sulphate solution. The colour disappears reversibly on the addition of a very small amount of substrate such as ascorbic acid or hydroquinone. It also disappears on boiling the enzyme or treating it with cyanide and diethyl-dithio-carbamate.

The activities of different preparations are proportional to their copper contents. All this shows that laccase is a copper-protein compound belonging to the same group of enzymes as the polyphenol oxidase of potatoes ${ }^{6}$ and of mushrooms ${ }^{5}$. If the poly. phenol oxidase of mushrooms containing 0.3 per cent copper is $90-100$ per cent pure the laccase preparation containing $0 \cdot 154$ per cent copper would be $45-50$ per cent pure. This laccase preparation, however, contains 55 per cent of a polysaccharide and only 6.45 per cent nitrogen, which corresponds to about 45 per cent protein. Assuming now that the polysaccharide is an impurity not connected with the enzyme and the copper is bound only to the protein, the copper content of the laccase protein would be about $0 \cdot 34$ per cent, which is the same as the copper content of crystalline hæmocuprein?. If one allows for the polysaccharide content of our purest preparation, the $Q_{02}$ of pure laccase would appear to be about 40,000 with $p$-phenylenediamine as substrate at $20^{\circ} \mathrm{C}$.

The activity of laccase is strongly inhibited by potassium cyanide, hydrogen sulphide, sodium azide and diethyl-dithio-carbamate but not by carbon monoxide, and this holds true whether catechol, $p$-phenylenediamine or ascorbic acid are used as substrates.

Although laccase belongs to the group of copperprotein enzymes, it differs in the following respects from the polyphenol oxidase of cultivated mushrooms (Psaliota campestris) :

(1) Laccase is distinctly blue while polyphenol oxidase is yellowish or colourless.

(2) Laccase oxidizes $p$-phenylenediamine better than catechol, while polyphenol oxidase scarcely attacks it.

(3) Laccase, when pure, does not oxidize $p$-cresol at all, while polyphenol oxidase in this reaction shows a distinct lag period, which, as we have shown, becomes more protracted on gradual purification of this enzyme 5 .

(4) Crude laccase preparation oxidizes ascorbic acid directly; this activity decreases on purification and can partly be restored by the addition of catalytic amount of $p$-phenylenediamine but not of catechol. Polyphenol oxidase, on the other hand, whether crude or pure, oxidizes ascorbic acid only through a carrier like catechol. The $Q_{0_{2}}$ of this latter reaction using only $0.02 \mathrm{mgm}$. catechol is still very large $(540,000)^{5}$.

(5) Laccase is not poisoned by carbon monoxide, while polyphenol oxidase, as we have shown, undergoes a very strong, although light-insensitive, inhibition by carbon monoxide ${ }^{5,8}$.

(6) The activity of laccase $\left(Q_{02}=40,000\right)$ is of the same order of magnitude as that given for potato oxidase $^{8}$. Both enzymes show only a twentieth of the activity of the polyphenol oxidase from cultivated mushrooms. This is clearly demonstrated especially when the activities of laccase and mushroom oxidase are estimated in the same way.

It may be mentioned that the purification of polyphenol oxidase from a wild mushroom (Lactarius vellereus) gave a yellowish preparation containing
0.2 per cent copper and having $Q_{0_{2}}$ of about 250,000 for catechol and of only 1,640 for $p$-phenylenediamine.

The results of this communication, apart from the fact that they reveal the nature and properties of laccase, are interesting in some other respects. They dispose of the criticism of our.work on the polyphenol oxidase of mushrooms made by Kubowitz ${ }^{9}$ who, without justification, assumes that the properties of different plant phenol oxidases must be the same as those of the potato oxidase. These results also serve as a warning against generalizations based on an incomplete knowledge of the subject and against the tendency of ascribing to one enzyme the properties of another enzyme in the same class, contrary to all the available evidence.

\section{Molteno Institute,}

D. KeILIN.

University of Cambridge.

T. ManN. Dec. 7.

'Yoshida, H., J. Chem. Soc., 43, 472 (1883).

' Bertrand, G., C.R., 118, 1215 (1894).

${ }^{3}$ Suminokura, K., Biochem. Z., 224, 292 (1930); Bull. Chem. Soc. Japan, 11, 299 (1936).

"Brooks, G., "Laque d'Indochine", Actualité scientiflques et industrielles, No. 94, 1-100 (1934).

${ }^{5}$ Keilin, D., and Mann, T., Proc. Roy. Soc., B, 125, 187 (1938).

- Kubowitz, F., Biochem. Z., 292, 221 (1937).

${ }^{7}$ Mann, T., and Keilin, D., Nature, 142, 148 (1938).

' Keilin, D., Proc. Roy. Soc., B, 104, 206 (1929).

- Kubowitz, F., Biochem. Z., 299, 32 (1938).

\section{The Sympathetic Character of the Nucleus Supraopticus}

IN a recent publication dealing with the question of whether nerve fibre terminals or pituicytes in the pars nervosa of the pituitary secrete the hormones pitocin and pitressin ${ }^{1}$, I quoted Ranson, Kabat and Magoun $^{2}$ as holding the view that the nucleus supraopticus of the hypothalamus was sympathetic in character. I was under the impression that the hypothalamic sympathetic centre, which extends to the chiasm, also included the nucleus supraopticus. On re-reading their work, it was found that a small paragraph had been overlooked in which it is definitely stated that there was no evidence that the nucleus supraopticus was included in this sympathetic centre.

I apologize to these authors for this error and retract the above-mentioned quotation. However, other evidence quoted (Kappers ${ }^{3}$ ) indicates that the nucleus supraopticus is sympathetic. Crouch and Elliott ${ }^{4}$ found that sympathetic reactions were regulated by the hypothalmus as a whole; but better responses were obtained from anterior and lateral nuclei. Because of this, I think that the nerve terminals of the hypothalamicohypophyseal tract are either adrenergic or cholinergic, as are the terminals of other autonomic fibres, and do not secrete the characteristic nervosa hormones.

Mervyn GRIFfiths.

Montreal Neurological Institute,

3801 University Street,

Montreal.

Dec. 3.

${ }^{1}$ Griffiths, Proc. Linn. Soc. N.S.W., 63, pts. 3-4, 81 (1938).

${ }^{2}$ Ranson, Kabat and Magoun, Arch. Neurol. and Psychiat., 33, 467 (1935).

${ }^{3}$ Kappers, "Three Lectures on Neurobiotaxis and other Subjects" (William Heinemann (Medical Books), Ltd., 1928).

${ }^{4}$ Crouch and Elliott, Amer. J. Physiol., 115, 245 (1936) 